Guido Cozzi, Ornella Tarola

\title{
Mergers, innovation, and inequality
}

Quaderno N. 03-10

Decanato della Facoltà di Scienze economiche

Via G. Buffi, $13 \mathrm{CH}-6900$ Lugano 


\author{
Mergers, Innovation, and Inequality \\ Guido Cozzi, Ornella Tarola \\ University of Rome "La Sapienza" and Catholic University of Louvain
}

October, 2003

\begin{abstract}
This paper presents a standard endogenous growth framework in which the source of growth is represented by vertical innovation. The crucial assumption we introduce is that there is a positive information-gap concerning the discovery of innovation. The aim of reducing the information dissemination lag provides incentives for firms to decide to merge their research efforts. At the same time we find that the skilled/unskilled wage gap is strongly related to this phenomenon. We prove that changing antitrust attitudes toward efficiency motivated mergers in contestable industries may simultaneously explain observed changes in the industry structure, in qualitative innovation, in wage inequality, and in labor supply composition.
\end{abstract}

JEL classification L25, L40, O31

Keywords: Growth; Firm-Size; Innovation Process; Antitrust Policy.

\title{
1. INTRODUCTION
}

Since the late seventies at least in the United States a relevant merger wave started and at the same time the overall wage inequality rose, the returns to college education increased, and product quality innovation intensified ${ }^{1}$.

Great attention has been paid by economists on mergers and acquisitions: the character of mergers is viewed as a mean to reallocate resources according to the most efficient criterion (Jovanovic and Rousseau 2001). It can be classified as either expansionary or contractionary (Andrade and Stafford 1999) ${ }^{2}$ depending on whether firms are supposed to expande their productive capacity or rationalize their operations and remove duplication project risks (Jensen 1993, Mitchell and Mulherin 1996). Regardless of the motives for firms to merge, merger waves seem to be associated to the environment's economic changes. The view that firms reallocate resources more effectively through mergers suggest a link between technolgical change and industry structure: when a new technology is introduced in a economic system, not all the firms would be easily able to run the technology and those firms having expertise in the newest technology can therefore takeover the disadvantaged ones starting a merger

\footnotetext{
${ }^{1} \mathrm{~A}$ stricking example is the information and communication technology revolution.

${ }^{2}$ Previous research sharing the same charateristics is by Bagwell and Shoven (1988).
} 
wave and enhancing growth (Jovanovic and Rousseau 2001, Carrol and Hanan 2000, Faria 2002) ${ }^{3}$. Several empirical approaches evaluating mergers' impacts on the economic context conclude for a positive relation between firms' economic performance and takeovers (Lichtenberg and Siegel 1990, Lichtenberg 1992), consistently with the "reallocation according efficiency" theoretical view. Moreover, it seems that those firms involved in an acquisitions process increase their R\&D expenses above the sectoral average level and the increased $\mathrm{R} \& \mathrm{D}$ investment is likely associated with higher profitability (Mcdougall 1995).

Unsurprisingly, the radical shifts in the distribution of wages that took place since the seventies has risen a significant interest in analyzing the potential explanations of this phenomenon. While there is a common consensus in the literature that wage inequality is due to the nature of technological change which, being skilled-biased has favored the skilled workers (Greenwood, Hercowitiz and Krussel 1997, Greenwood and Yorucoglu 1997), a strand of thought points its attention to a complex set of heterogenous factors acting with the skilled-bias to explain wage inequality: labor market organization, institutional change and trade. Labor market has been reorganized consistently with the pervasive recent technologies destroying several types of high pay-unskilled workers jobs (Kremer and Maskin 1999, Acemoglu 1999). Istitutional change consisting for the most part in deunionization process has weakened the bargaining power of the skilled workers (Freeman 1991). And finally international trade with developing countries has significantly increased the number of less-skilled workers, depressing their marginal value product (Acemoglu 2002).

Although these research lines represent a continuous advancement in understanding the above mentioned issues, their reference frameworks are separate sets, each solely concerned with its own stylized fact. The aim of this paper is to suggest a way to fill this gap.

This paper presents an R\&D-driven growth model sharing several features with the well-known Aghion and Howitt's (1992 and 1998) basic Schumpeterian model, in which the source of growth is represented by vertical (product quality improving) innovation. Our analysis takes two aspects of innovating explicitly into account: the discovery and the patenting of innovation. The crucial assumption of this model is precisely that the time when the discovery of innovation is made by a first firm is supposed to be unknown by the other firms. It becomes common knowledge when both the first step and the second one are concluded. Hence, there is a period of time when the firms do useless research effort. The realism of this assumption has been emphasised by Shapiro (2002, p.16): "since no disclosure is required when patent application is filed, companies introducing new products that incorporate state-ofthe-art technology may find that they are unwittingly infringing on patents issued

\footnotetext{
${ }^{3}$ The argument had been introduced by Gort (1969).
} 
after their product design decisions were made and significant resources were sunk in developing the new product." Due to this information-gap negatively affecting research-effort, a form of congestion appears in the $\mathrm{R} \& \mathrm{D}$ sector.

Consistently with these assumptions, our findings are twofold.

First of all, we show that the aim of reducing the information dissemination lag provides the incentives for $\mathrm{R} \& \mathrm{D}$ firms to decide to merge, and for $\mathrm{R} \& \mathrm{D}$ workers to cooperate with each others. This finding is consistent with the view according to which mergers can occur as a result of firms following efficiency criteria. Moreover, it seems to confirm the point that often firms decide to cooperate through a form of ex-ante R\&D cooperation aimed at reducing the risk of duplicating projects. Indeed any agreement to eliminate the information dissemination lag makes R\&D investment more efficient and enhances growth. At the same time we find that the skilled/unskilled wage gap is strongly related to the number of (cooperating groups of) firms in the economy: the higher the number of research-firms, the lower the probability of a firm winning the $R \& D$ race and the expected value of an hour in research; the higher the number of firms in the market, the stronger the effects of the information-gap, the lower the skilled labor demand and the expected aggregate growth rate, and the lower the skilled/unskilled wage gap. In this sense our model provides an additional explanation of the above mentioned stylized fact.

Incidentally, our assumed information lag proves sufficient to purge a scale effect problem (Jones 1995 and 1999) suffered by the early generation endogenous growth models, such as Aghion and Howitt (1992), despite increasing returns in the production of ideas and a number of sectors that does not increase with population.

The remainder of this paper is organized as follow. Section 2 introduces the basic framework of the model. Section 3 presents the balanced growth properties of the market economy. Section 4 analyses the relationship between market structure, R\&D activity, and economic growth. Section 5 endogenizes skilled labor supply. Finally some conclusions are drawn.

\section{BASIC FRAMEWORK}

In this section we will introduce a new ingredient - information lag - into the basic Schumpeterian model of Aghion and Howitt (1992 and 1998). We will derive the main consequences in the next sections. As we shall see this new element suffices in delivering strong implications about the relationship between concentration and growth - reviving some of Schumpeter's (1942) intuitions - as well about the growth properties of the model.

The economy is populated by a continuum of infinitely-lived individuals with linear intertemporal preferences

$$
u(y)=\int_{0}^{\infty} y_{t} e^{-r \tau} d \tau
$$


where $r$ is a constant rate of time preference.

Due to perfect capital markets and linear preferences, the equilibrium interest rate will be constant and equal to $r$. There are three sectors, the final output, the intermediate, and the research an development (R\&D) sector. The final output and the R\&D sectors are supposed to be perfectly competitive while the intermediate good sector has monopolistic structure: the firm that is the successful innovator retains a temporary monopoly rent on the production of the intermediate good until replaced by the next innovator. There are two categories of labor: the skilled labor $L$ which is employed both in the manufacturing sector and in the R\&D one and the unskilled labor $M$ which is used in producing the final output sector. In the final output sector the consumption good is produced by using a fixed amount $M$ of unskilled labor -that can be employed only in the final output sector- normalized to 1,and intermediate goods $x$ according to the following production function.

$$
y_{t}=F(M, x)=A_{t} x_{t}^{\alpha}
$$

Labor market equilibrium implies:

$$
L_{t}=x_{t}+n_{t}
$$

let $w$ and $w^{u}$ the wage rate for skilled and unskilled labor respectively, and $\omega_{t} \equiv$ $w_{t} / A_{t}$ the productivity-adjusted skilled wage.

The intermediate monopolist's profit maximization problem yields the usual expression:

$$
\pi_{t}=\left(\frac{1-\alpha}{\alpha}\right) w_{t} x_{t} \equiv A_{t} \tilde{\pi}\left(\omega_{t}\right)
$$

In the R\&D sector the discovery of a better quality of intermediate goods comes in two steps - two phases of a single cycle-:

- a new intermediate good is discovered -first phase

- after the discovery the firms takes time to patent the new intermediate good -second phase

Innovations' use raises the technology parameter by a constant factor $\gamma>1$.

We follow the standard Schumpeterian approach of modeling each R\&D race as an inventing lottery: at the beginning of the $\mathrm{R} \& \mathrm{D}$ race each research-firm participates in $R \& D$ race with equal likelihood to discover the highest quality intermediate good -first phase. The arrival rate of innovations $\lambda n$ is governed by a Poisson process: $\lambda$ 
represents the productivity of research technology and $n$ the amount of labor employed in R\&D. However once discovered the better quality of intermediate good, a fixed interval of time-defined $\delta$ - is needed to patent the innovation -second phase.

The time $\tau$ when the discovery is made -hence the length of the first phase- by a first firm -that is the winner of the $R \& D$ race- is supposed to be unknown by the other firms. Moreover the winner starts to earn profits due to his discovery after a complete cycle: no profit is earned before a whole cycle is closed. The patent expires when a next intermediate goods with higher quality is introduced in the economic system -that is when a next cycle is concluded.

However due both to the structure of the two phases needed to complete a whole cycle and to the fixed length of the second phase, the relevant time for a $R \& D$ firm to consider is that one after which an interval of length equal to $\delta$ has not passed: indeed nothing can be said concerning the innovation having happened during this period because precisely a length of time $\delta$ is needed to patent the latest innovation.

In the $R \& D$ sector the winner is earns thepresent value of the returns from discovering and patenting the higher quality intermediate goods:

$$
V_{t+1}=\left[\pi_{t+1}-\lambda n_{t+1}\left(V_{t+1}-\bar{V}_{t+1}\right)\right] / r
$$

where the LHS represents the profit flow $\pi_{t+1}$ due to the discovery of $t+1$ intermediate good minus the capital loss $\lambda n_{t+1}\left(V_{t+1}-\bar{V}_{t+1}\right)$ due to the finite length of monopoly rent.

The term $\bar{V}_{t+1}$ is linked to the structure of a cycle: a kind of delay is introduced in this asset equation since no research-firm is replaced by a new innovator until the second phase is closed. In other words the present value disappears some time after the discovery of the next generation of intermediate good, when both the first phase and the second one are concluded.

Consistently with this assumption it follows

$$
r \bar{V}_{t+1}=\pi_{t+1}\left(1-e^{-r \delta}\right)
$$

By combining both (2) and (3), it follows

$$
V_{t+1}=\frac{\pi_{t+1}+\lambda n_{t+1} \bar{V}_{t+1}}{r+\lambda n_{t+1}}=\frac{\left[r+\lambda n_{t+1}\left(1-e^{-r \delta}\right)\right] \pi_{t+1} / r}{r+\lambda n_{t+1}}
$$

The denominator of the previous expression $r+\lambda n_{t+1}$ represents the obsolescenceadjusted interest rate (see Aghion and Howitt 1992, Aghion and Howitt 1998, ch. 2): the second term $\lambda n_{t+1}$ can be intended as a creative-destruction rate linked to the obsolescence affecting the innovation. The higher the research level in the next period the higher the creative-destruction rate the lower the present value of an innovation. 


\section{Balanced Growth}

For brevity reasons we will here perform only balanced growth analysis. It is not too difficult to prove that explicitly incorporating transitional paths all quantities and prices tend to converge monotonically to the steady state values ${ }^{4}$.

The amount of labor to employ in the R\&D sector is determined by the following arbitrage condition:

$$
w_{t}=e^{-\lambda \delta \int_{0}^{\delta} n_{t}(s) d s} \lambda V_{t+1} e^{-r \delta}
$$

according to which the value of an hour in manufacturing $\left(w_{t}\right)$ has to be equal to the expected value of an hour in research. The RHS representing precisely the expected value of an hour in research has to include both the terms $e^{-\lambda \delta \int_{0}^{\delta} n_{t}(s) d s}$ and $e^{-r \delta}$. The first one represents the probability that the highest quality intermediate good could have already been discovered ${ }^{5}$ Moreover the integral $\int_{0}^{\delta} n_{t}(s) d s$ refers to the uncertainty concerning the innovation process: since no firm knows the time of the discovery, the more the time after the end of prevoius cycle, the less the success probability in the $R \& D$ race, the less the incentive to research. The second term is linked to the timing of innovating. The present value of a higher quality intermediate good appear some time after its discovery: because of it $e^{-r \delta}$ has to be introduced in the arbitrage condition.

By combining the (5) and (4) and the considerations concerning $\pi(w)$ and $\tilde{\pi}(\omega)$ the arbitrage condition can be re-written

$$
\omega_{t}=e^{-\lambda \delta \int_{0}^{\delta} n_{t}(s) d s} e^{-r \delta} \lambda \frac{\gamma\left[r+\lambda n_{t+1}\left(1-e^{-r \delta}\right)\right] \tilde{\pi}_{t+1} / r}{r+\lambda n_{t+1}}
$$

Similarly to Aghion and Howitt (1992), the amount of research employment $\bar{n}$ in a stationary equilibrium can be evaluated as follows

$$
\frac{\omega}{e^{-\lambda \delta n} \lambda e^{-r \delta}}=\frac{\gamma\left[r+\lambda n\left(1-e^{-r \delta}\right)\right] \tilde{\pi} / r}{r+\lambda n}
$$

\footnotetext{
${ }^{4}$ See Tarola (2002, ch. 3) for detailed calculations.

${ }^{5}$ This probability is equal to 1 minus the probability that the higher quality intermediate good has been discovered, that is $1-\left(1-e^{-\lambda \tau_{\delta} \int_{0}^{\delta} n_{t}(\tau) d \tau}\right)$ where

$$
\begin{gathered}
\tau_{\delta}=\delta \text { if } \tau \geq \delta-\tau_{t} \\
\tau_{\delta}=\tau-\tau_{t} \text { if } \delta>\tau-\tau_{t}
\end{gathered}
$$
}

We focus the attention on the case $\tau_{\delta}=\delta$. For details see Tarola (2002). 
It is higher the lower the interest rate $r$, the higher the size of innovation $\gamma$, the higher the arrival rate of innovation $\lambda$,the higher the total amount of labor force $L$

By manipulating the $(7)$ it follows

$$
\omega=e^{-\lambda \delta \bar{n}} \lambda \gamma e^{-r \delta} \frac{\left[r+\lambda \bar{n}\left(1-e^{-r \delta}\right)\right]\left(\frac{1-\alpha}{\alpha}\right) \omega x / r}{r+\lambda \bar{n}}
$$

and hence:

$$
\frac{e^{\lambda \bar{n} \delta} e^{r \delta}}{\lambda \gamma \bar{n}}=\left(1-\frac{e^{-r \delta}}{\frac{r}{\lambda \bar{n}}+1}\right)\left(\frac{1-\alpha}{\alpha}\right)\left(\frac{L}{\bar{n}}-1\right) / r
$$

from which we get:

$$
\frac{\vartheta(L / \bar{n})}{\vartheta L}>0
$$

Hence an increase in $L$ raises the ratio $L / \bar{n}$. Not too surprisingly any increase in the labor force, that is in the population size, does not raise proportionally the research labor. This is due to that the $\mathrm{R} \& \mathrm{D}$ sector is supposed to be subject to a kind of congestion. The term $e^{-\lambda \bar{n} \delta}$ refers precisely to this congestion: the higher the amount of labor devoted to research the lower from an individual firm's perspective the chance of winning the $R \& D$ race and the less profitable to invest in $R \& D$ activities.

As far as the balanced growth is concerned the final output good during the time interval $t$ can be written as

$$
y_{t}=A_{t}(L-\bar{n})^{\alpha}
$$

hence it follows

$$
y_{t+1}=\gamma y_{t}
$$

As in Aghion and Howitt (1992 and 1998) we can write

$$
\ln y(\tau+1)=\ln y(\tau)+\varepsilon(\tau)
$$

where $\tau$ refers to real time and $\varepsilon$ the number of innovations between $\tau$ and $\tau+1$.

The crucial point is represented by $\varepsilon$ : in this framework the number of innovations is bounded above.

This is due to the timing of the model according to which on one hand researchfirms need to see the previous innovation before anyone can think of the new one, on the other hand an innovation becomes known just after both the first phase and the second one are closed. 
During the second phase in spite of the discovery made in the first one no new innovation can be introduced in the system -regardless of the $R \& D$ effort- due to that no firm knows what has already happened. Hence the average growth rate of the economy is

$$
g=\sum_{j=0}^{\kappa} \frac{(\lambda n \tau)^{j} e^{-\lambda n \tau_{\delta}}}{j !} j \ln \gamma=\lambda m(n) \ln \gamma
$$

where $\lambda m(n)=\sum_{j=0}^{\kappa} \frac{(\lambda n \tau)^{j} e^{-\lambda n \tau} \delta}{j !} j$ which is bounded above by $\kappa \equiv \frac{1}{\delta}$. Hence regardless of the amount of skilled labor the information/dissemination lag puts an upper bound to percapita growth rate, thereby eliminating the well known scale effect property of Aghion and Howitt (1992) proved by Jones (1995) to be inconsistent with existing data.

\section{Concentration and Cooperation in the R\&D Sector}

The main feature of the decentralized setting is the congestion phenomenon due to the information-gap affecting negatively research-effort. This is rather realistic in an economy in which a large number of small firms undertake independent R\&D projects. In the model of the previous section this was stylized by the assumption of zero-measure firms. Though in the real industrial world it is frequent for small firms to exchange some relevant information with each other, the character of a firm as an information barrier (Jovanovic and Rob 1989, Jovanovic and MacDonald 1994, Jovanovic and Rousseau 2001) provides strong incentives for firms to merge their R\&D units or to let them cooperate (Cozzi 1999). In this model with free entry, tradable factors, and constant returns homogeneous R\&D workers extract all producer's surplus generated: hence large firms can be equivalently be seen as skilled workers' $\mathrm{R} \& \mathrm{D}$ associations. The aim of reducing the information dissemination lag provides a natural motivation for R\&D firms to merge and/ for R\&D workers to cooperate with each other. Of course, the antitrust authorities should worry that a cartel of R\&D producers might refrain from innovation by internalizing the business stealing externality. Hence it seems important to investigate which firm size is the more adequate system to overcome this sort of congestion without discouraging aggressive innovative activity. The aim of this section is precisely to define the number of research-firms that maximizes growth.

The relationship between the number of research-firms and research-effort has to be verified. We can assume that $N$ research-firms participate in R\&D race ${ }^{6}$. Any research-firm $i$ devotes exactly $n_{t}^{i}$ to $\mathrm{R} \& \mathrm{D}$ sector with

$$
n_{t}^{i} \equiv \frac{n_{t}}{N}
$$

\footnotetext{
${ }^{6}$ In the following analysis we assume $N \geq 2$.
} 
where $n_{t}$ is the total amount of labor employed in the research-sector.

In the determination of its $R \& D$ effort each firm cares about the probability of winning the $R \& D$ race. This is inversely related to $R \& D$ effort of the other researchfirms.

Focusing on symmetric equilibria we can re-write the arbitrage condition for the firm $i$ as follows:

$$
\omega_{t}=e^{-\lambda \frac{(N-1)}{N} n_{t} \tau_{\delta}} e^{-r \delta} \lambda \frac{\gamma\left[r+\lambda n_{t+1}\left(1-e^{-r \delta}\right)\right] \tilde{\pi}_{t+1} / r}{r+\lambda n_{t+1}}
$$

where $e^{-\lambda \frac{(N-1)}{N} n_{t} \tau_{\delta}}$ refers to the probability of success for the firm $i$. It is expressed in terms of the number of research-firms working in the market and total amount of labor employed in R\&D, and it can be seen that RHS is a decreasing function of $N$. The following holds:

Proposition 1. The higher the number of non-cooperating research firms, $N$, the lower the probability of a firm's winning the $R \& D$ race, the lower the expected value of an hour in research. The higher the number of firms in the market the stronger the effects of the information-gap, the lower the expected aggregate growth rate, and the lower the skilled/unskilled wage gap.

Proof. Let us rewrite the arbitrage condition as

$$
\phi\left(n_{t}, N\right) \equiv e^{-\lambda \frac{(N-1)}{N} n_{t} \delta} e^{-r \delta} \lambda \frac{\gamma\left[r+\lambda n_{t+1}\left(1-e^{-r \delta}\right)\right] \tilde{\pi}_{t+1} / r}{r+\lambda n_{t+1}}-\omega_{t}=0
$$

Then according to the implicit function theorem we know that

$$
\frac{\partial n_{t}}{\partial N}=-\frac{\partial \phi(\bullet) / \partial N}{\partial \phi(\bullet) / \partial n_{t}}
$$

where

$$
\frac{\partial \phi(\bullet)}{\partial N}=-\lambda n_{t} \delta N^{-2} e^{-\lambda \frac{(N-1)}{N} n_{t} \delta} e^{-r \delta} \frac{\gamma\left[r+\lambda n_{t+1}\left(1-e^{-r \delta}\right)\right] \tilde{\pi}_{t+1} / r}{r+\lambda n_{t+1}}
$$

and

$$
\frac{\partial \phi(\bullet)}{\partial n_{t}}=-\lambda \frac{(N-1)}{N} \delta e^{-\lambda \frac{(N-1)}{N} n_{t} \delta} e^{-r \delta} \frac{\gamma\left[r+\lambda n_{t+1}\left(1-e^{-r \delta}\right)\right] \tilde{\pi}_{t+1} / r}{r+\lambda n_{t+1}}
$$

Hence it follows 


$$
\frac{\partial n_{t}}{\partial N}=-\frac{\partial \phi(\bullet) / \partial N}{\partial \phi(\bullet) / \partial n_{t}}<0
$$

since $\frac{\partial \phi(\bullet)}{\partial N}<0$ and $\frac{\partial \phi(\bullet)}{\partial n_{t}}<0$ that is the lower the number of research-firms the higher the equilibrium effort in $R \& D$ and the higher the average growth rate of the economy. The other statements follow straightforwardly. Q.E.D.

Hence due to that both the $R \& D$ effort is inversely related to the number of research-firms and the higher the research-effort the higher the average growth rate of the economy we can conclude that the best solution under laissez-faire is obtained when a minimum number of firms operate in the market that is when $N=2$. Since skilled workers are always better off the relatively larger their R\&D firm we can conclude:

Corollary 2. An antitrust policy that seeked to maximize growth would allow the formation of a non-collusive duopoly in the $R \& D$ sector, which would immediately form.

It is important to remark that here the duopoly emerges endogenously as R\&D workers would tend to unify their effort, but the antitrust authorities can allow or ban it. Hence at the R\&D stage every duopolist is under the constant threat of possible free entrants (defector groups of workers). Therefore all profits are dissipated into skilled wage.

4.1. Monopoly or Duopoly?. Should the antitrust authority allow R\&D firms

to join a unique firm, that will become the unique intermediate good monopolist ${ }^{7}$ ? We just need to compare (10) with $N=2$ to the following arbitrage condition of the monopolist:

$$
\omega_{t}=\lambda \frac{(\gamma-1) \tilde{\pi}_{t+1}}{r}
$$

and conclude that the larger the information lag, the higher the quality jump, and the more populated the economy the more innovative the monopoly compared to the duopoly. Reminding the reader that in this representative sector model the monopoly should be correctly interpreted as belonging to an infimum sub-sector of the whole economy, it may be interesting to note that our analysis implies that - ceteris paribus - when a large area integrates economically it is more likely that antitrust authorities

\footnotetext{
${ }^{7}$ Taken literally in Aghion and Howitt's (1992) economy the monoopolist would also have monopsonist power. However their macroeconomic focus - which is also ours - clarifies that it should be interpreted as a representative industry in a large set of industries.
} 
concerned with innovation would decide to allow more concentration than smaller areas. The reason is that with a large skilled labor mass working for the rival each duopolist would seriously fear that its potential discovery could already be - or will soon become - obsolete.

\section{Endogenous Skills}

Up to now we have being following Aghion and Howitt's (1992) assumption of a fixed composition of the labor supply between skilled and unskilled workers. In this section we show that our analysis allows to relate efficiency enhancing mergers to the endogenous composition of the labor force.

In fact it is straightforward to endogenize the suppy of skills in this economy, by adapting to the closed economy framework Dinopoulos and Segerstrom's (1999) methodology. We will assume that individuals are finitely lived members of infinitely lived households, being continuously born at rate $\beta$, and dying at rate $d$, with $\beta-d>$ $0 ; D>0$ denotes the exogenously given duration of their life. People are altruistic in that they care about their household's total discounted utility according to the usual intertemporally additive functional. They choose to train and become skilled at the beginning of their lives, and the (positive) duration of their training period - in which the individual cannot work - is exogenously fixed as $T<D$.

Hence an individual with ability $\theta \in[0,1]$ uniformely distributed decides to train if and only if the following is satisfied:

$$
E_{\tau}\left[\int_{\tau}^{\tau+D} e^{-r(s-\tau)} w^{u}(s) d s\right]<E_{\tau}\left[\int_{\tau+T}^{\tau+D} e^{-r(s-\tau)} \max (\theta-\gamma, 0) w(s) d s\right]
$$

with $0<\gamma<1 / 2$, and with $E_{\tau}$ denoting expectations as of time $\tau$. Notice that an individual of ability $\theta>\gamma$ is postulated able to accumulate skill (human capital) $\theta-\gamma$ after training, while individuals with too low ability $(\theta<\gamma)$ never get any skill from schooling.

As Dinopoulos and Segerstrom (1999) we focus on the steady state (balanced growth) analysis, in which all variables - and real wages in particular - are expected to grow at the same constant expected growth rate as $A_{t}$. Hence any individual will decide to get an education if and only if her ability level is no less than

$$
\theta_{0}=\sigma \frac{\omega^{u}}{\omega}+\gamma
$$

with $\sigma>0$ being a parameter dependent constant. Therefore the aggregate supply of unskilled labor at time $t$ is

$$
M(\tau) \equiv \theta_{0} L(\tau)=\left(\sigma \frac{\omega^{u}}{\omega}+\gamma\right) L(\tau)
$$


and the aggregate supply of skilled labor at time $\tau$ is

$$
L^{s}(\tau)=\left(\theta_{0}+1-2 \gamma\right)\left(1-\theta_{0}\right) \phi L(\tau) / 2
$$

with $0<\phi<1$.

Since the fraction of the population that decides to get skilled is only dependent on the productivity adjusted skilled/unskilled wage ratio and on parameters the results of the previous sections continue to hold and we can state:

Proposition 3. The lower the number of non-cooperating $R \& D$ firms, $N$, the higher expected aggregate growth rate, the higher the skilled/unskilled wage gap, and the larger the fraction of population that decides to get skilled.

Proof. Just repeat the proof of Proposition 1 using (12) and (13) instead of $M=1$ and $L$.

\section{Conclusion}

In this paper we have shown that due to the information gap between research firms a kind of congestion appears in the R\&D sector. This phenomenon, reducing the research effort, affects negatively growth. Moreover being $R \& D$ effort inversely related to the number of non-cooperating research firms, we conclude that the most growth enhancing policy under laissez-faire is to allow at least a contestable duopoly for each innovative industry. It seems interesting that the information dissemination lag allows us to capture in a unified framework phenomena - such as the wage inequality, mergers and their interplay - analysed in often unrelated investigation, although with similar time pattern.

It seems interesting to re-interpret some recent trends in the US and EU in light of our simple model's results. Since the mid 70's - also due to weaker international barriers and fierce competition by newly industrialized countries - US and EU authorities have relaxed their antitrust policy against mergers and R\&D cooperation in order to improve their competitiveness. This has stimulated R\&D efforts, reduced innovation delay (see Agarwal and Gort, 2000), improved product qualities at a faster rate, and at the same time it has increased wage inequality and the fraction of the highly educated population.

Although our results, being presented in a new analysis perspective, seem consistent with the real world empirical evidence on intefirm barriers, the related incentives for firms to cooperate, and the plausibile link between market structure, wage inequality, and growth, yet they have been obtained within the extremely stylized Aghion and Howitt's (1992) framework. It would be interesting to extend our logic to an explicitly more complex frameworks, such as for example Aghion et al. (2001). 


\section{References}

Acemoglu D. (1999). "Changes in Unemployment and Wage Inequality: an Alternative Theoryand Some Evidence", American Economic Review 89, 1259-78

Acemoglu D.(2002) "Technical Change, Inequality and The Labor Market", Journal of Economic Literature XL, 7-12.

Agarwal R. and M. Gort (2000). "First Mover Advantage and the Speed of Competitive Entry, 1887-1986", Manuscript, SUNY at Buffalo.

Aghion P. and P. Howitt (1992). "A Model of Growth Through Creative Destruction," Econometrica 60, 323-351.

Aghion P. and P. Howitt (1998). Endogenous Growth Theory. Cambridge: MIT Press.

Aghion, P., Howitt, P., Harris, C., and J. Vickers (2001), "Competition, Imitation, and Growth with Step-by-Step Innovation", Review of Economic Studies 28, 467-92.

Andrade G. and E. Stafford (1999). "Investing the Economic Role of Mergers", Working Paper, Harvard Business School.

Bagwell L. and J. Shoven (1988). "Share Repurchases and Acquisitions: An Analysis of Which Firms Participate", in A.J. Auerbach, ed, Corporate Takeovers: Causes and Consequences, University of Chicago Press/NBER, Chicago, IL.

Carrol G. and T.M. Hanan (2000). The Demography of Organizations and Industries, Princeton University Press, Princeton, N.Y.

Cozzi G. (1999). "R\&D Cooperation and Growth". Journal of Economic Theory 86, 17-49.

Dinopoulos E. and P. Segerstrom. (1999). "A Schumpeterian Model of Protection and Relative Wages," American Economic Review 89, 450-472.

Faria L.A. (2002). "Mergers and the Market for Organization Capital, Working Paper, University of Chicago.

Freeman R. (1991) "How Much Has De-unionization Contributed to the Rise of Male Earnings Inequality?" Working Paper, NBER.

Gort M. (1969). "An Economic Disturbance Theory of Mergers", Quarterly Journal of Economics 83, 624-42.

Greenwood J., Hercowitiz Z. and Krussel P. (1997). "Long-Run Implications of Investment-Specific Technological Change", American Economic Review 87:3, 34262 .

Greenwood J. and Yorucoglu (1997). "1974", Carnegie-Rochester Conference Ser. Public Pol. 46, 49-95.

Jensen M. (1993). "The Modern Industrial Revolution, Exit and Control System", Journal of Finance, 831-880.

Jones, C. (1995), "R\&D Based Models of Economic Growth". Journal of Political Economy 103: 759-84. 
Jones C. (1999). "Growth: With or Without Scale Effects?" American Economic Review 89, 139-144.

Jovanovic B. and G. MacDonald (1994). "Competitive Diffusion," Journal of Political Economy 102, 24-52.

Jovanovic B. and R. Rob (1989). "The Growth and Diffusion of Knowledge," Review of Economic Studies 56, 569-582.

Jovanovic B. and P Rousseau (2001) "Mergers and Technological Change: 1885$1998 "$.

Kremer M. and Maskin E. (1999). "Segregation by Skill and the Rise in Inequality", Harvard Mimeo.

Lichtenberg F. R. and D. Siegel (1990). "The Effects of Leveraged Buyouts on Productivity and Related Aspects of Firm Behaviour", Journal of Financial Economics 27, 165-94.

Lichtenberg F. R. (1992). Corporate Takeovers and Productivity. Cambridge: MIT Press.

Mcdougall G. (1995). "The Economic Impact of Mergers and Acquisitions on Corporations". Micro-Economic Policy Analysis, Canada Industry.

Mitchell M. and J. Mulherin (1996). "The Impact of Industry Shocks on Takeover and Restucturing Activity", Journal of Financial Economics 193-229.

Morck R, A. Shleifer and R. Vishny (1988). "Charateristics of Target of Hostile and Friendly Takeovers" in A.J. Auerbach, ed, Corporate Takeovers: Causes and Consequences, University of Chicago Press/NBER, Chicago, IL.

Schumpeter J. A. (1942). Capitalism, Socialism and Democracy. New York: Harper \& Row.

Shapiro C. (2002). "Competition Policy and Innovation". Working Paper 2002/11, DSTI.

Tarola, O. (2002). "Essays in Schumpeterian Growth Theory", PhD Dissertation, University of Rome "La Sapienza". 


\title{
QUADERNIDELLA FACOLTÀ
}

\author{
I quaderni sono richiedibili (nell'edizione a stampa) alla Biblioteca universitaria di Lugano \\ via G. Buffi 13 CH 6900 Lugano \\ e-mail: biblioteca@lu.unisi.ch
}

The working papers (printed version) may be obtained by contacting the Biblioteca universitaria di Lugano via G. Buffi 13 CH 6900 Lugano

e-mail: biblioteca@lu.unisi.ch

Quaderno n. 98-01

P. Balestra, Efficient (and parsimonious) estimation of structural dynamic error component models

Quaderno n. 99-01

M. Filippini, Cost and scale efficiency in the nursing home sector : evidence from Switzerland

Quaderno n. 99-02

L. Bernardi, I sistemi tributari di oggi : da dove vengono e dove vanno

Quaderno n. 99-03

L.L. Pasinetti, Economic theory and technical progress

Quaderno n. 99-04

G. Barone -Adesi, K. Giannopoulos, L. Vosper, VaR without correlations for portfolios of derivative securities

Quaderno n. 99-05

G. Barone-Adesi, Y. Kim, Incomplete information and the closed-end fund discount

Quaderno n. 99-06

G. Barone -Adesi, W. Allegretto, E. Dinenis, G. Sorwar, Valuation of derivatives based on CKLS interest rate models

Quaderno n. 99-07

M. Filippini, R. Maggi, J. Mägerle, Skalenerträge und optimale Betriebsgrösse bei den schweizerische Privatbahnen

Quaderno n. 99-08

E. Ronchetti, F. Trojani, Robust inference with GMM estimators

Quaderno n. 99-09

G.P. Torricelli, I cambiamenti strutturali dello sviluppo urbano e regionale in Svizzera e nel Ticino sulla base dei dati dei censimenti federali delle aziende 1985, 1991 e 1995 
Quaderno n. 00-01

E. Barone, G. Barone-Adesi, R. Masera, Requisiti patrimoniali, adeguatezza del capitale e gestione del rischio

Quaderno n. 00-02

G. Barone-Adesi, Does volatility pay?

Quaderno n. 00-03

G. Barone-Adesi, Y. Kim, Incomplete information and the closed-end fund discount

Quaderno n. 00-04

R. Ineichen, Dadi, astragali e gli inizi del calcolo delle probabilità

Quaderno n. 00-05

W. Allegretto, G. Barone-Adesi, E. Dinenis, Y. Lin, G. Sorwar, A new approach to check the free boundary of single factor interest rate put option

Quaderno n. 00-06

G.D.Marangoni, The Leontief Model and Economic Theory

Quaderno n. 00-07

B. Antonioli, R, Fazioli, M. Filippini, Il servizio di igiene urbana italiano tra concorrenza e monopolio

Quaderno n. 00-08

L. Crivelli, M. Filippini, D. Lunati. Dimensione ottima degli ospedali in uno Stato federale

Quaderno n. 00-09

L. Buchli, M. Filippini, Estimating the benefits of low flow alleviation in rivers: the case of the Ticino River

Quaderno n. 00-10

L. Bernardi, Fiscalità pubblica centralizzata e federale: aspetti generali e il caso italiano attuale

Quaderno n. 00-11

M. Alderighi, R. Maggi, Adoption and use of new information technology

Quaderno n. 00-12

F. Rossera, The use of log-linear models in transport economics: the problem of commuters' choice of mode

Quaderno n. 01-01

M. Filippini, P. Prioni, The influence of ownership on the cost of bus service provision in Switzerland. An empirical illustration

Quaderno n. 01-02

B. Antonioli, M. Filippini, Optimal size in the waste collection sector

Quaderno n. 01-03

B. Schmitt, La double charge du service de la dette extérieure 
Quaderno n. 01-04

L. Crivelli, M. Filippini, D. Lunati, Regulation, ownership and efficiency in the Swiss nursing home industry

Quaderno n. 01-05

S. Banfi, L. Buchli, M. Filippini, Il valore ricreativo del fiume Ticino per i pescatori

Quaderno n. 01-06

L. Crivelli, M. Filippini, D. Lunati, Effizienz der Pflegeheime in der Schweiz

Quaderno n. 02-01

B. Antonioli, M. Filippini, The use of a variable cost function in the regulation of the Italian water industry

Quaderno n. 02-02

B. Antonioli, S. Banfi, M. Filippini, La deregolamentazione del mercato elettrico svizzero e implicazioni a breve termine per l'industria idroelettrica

Quaderno n. 02-03

M. Filippini, J. Wild, M. Kuenzle, Using stochastic frontier analysis for the access price regulation of electricity networks

Quaderno n. 02-04

G. Cassese, On the structure of finitely additive martingales

Quaderno n. 03-01

M. Filippini, M. Kuenzle, Analisi dell'efficienza di costo delle compagnie di bus italiane e svizzere

Quaderno n. 03-02

C. Cambini, M. Filippini, Competitive tendering and optimal size in the regional bus transportation industry

Quaderno n. 03-03

L. Crivelli, M. Filippini, Federalismo e sistema sanitario svizzero

Quaderno n. 03-04

L. Crivelli, M. Filippini, I. Mosca, Federalismo e spesa sanitaria regionale : analisi empirica per i Cantoni svizzeri

Quaderno n. 03-05

M. Farsi, M. Filippini, Regulation and measuring cost efficiency with panel data models : application to electricity distribution utilities

Quaderno n. 03-06

M. Farsi, M. Filippini, An empirical analysis of cost efficiency in non-profit and public nursing homes

Quaderno n. 03-07

F. Rossera, La distribuzione dei redditi e la loro imposizione fiscale : analisi dei dati fiscali svizzeri 
Quaderno n. 03-08

L. Crivelli, G. Domenighetti, M. Filippini, Federalism versus social citizenship : investigating the preference for equity in health care

Quaderno n. 03-09

M. Farsi, Changes in hospital quality after conversion in ownership status

Quaderno n. 03-10

G. Cozzi, O. Tarola, Mergers, innovations, and inequality 